Canberra, recently professor of physics in the University of Birmingham, has perhaps summed up the situation as well as anyone in a remark to the Canberra correspondent of The Times: "There is nothing impossible about it, and I would very much like to know more of it".

\section{Barker Index of Crystals}

WITHIN the next few months the first volume of the "Barker Index of Crystals", edited by Dr. M. W. Porter and R. C. Spiller, Department of Mineralogy, University Museum, Oxford, will appear, and will provide for the first time a simple and practical method for the identification of chemical substances by the measurement of their crystal angles. One of the several advantages to the chemist of this method of identification is that the crystal used for measurement may be as small as $\frac{1}{2} \mathrm{~mm}$. $\times \frac{1}{2} \mathrm{~mm} . \times \frac{1}{2} \mathrm{~mm}$., and it will be intact at the end of the investigation. Another advantage is that the identity of a complicated organic compound can be determined in incomparably shorter time than a chemical analysis would take. It is well known that many chemical substances form crystals bounded by plane faces, and that the angles between the faces are characteristic of the particular chemical substance. The crystal angles of many compounds have been recorded in the literature for well over one hundred years, and the fact that they have not been generally used as a means of identification is due to the lack of a practical method of using them. The difficulty lies in the fact that crystals may possess many faces and therefore many interfacial angles. This leads to a wide choice in the selection of classification angles. Dr. T. V. Barker, of Oxford, proposed a method of meeting this difficulty and described it in a small book, "Systematic Crystallography" (1930), with the intention of following it up with a large index of crystal angles. $\mathrm{He}$ died in 1931, but his plan has been carried out since that date by a number of English and foreign erystallographers with headquarters at Oxford. An interim report on the progress of this work was given in Nature, 144, 298 (1939). The first volume of the "Barker Index of Crystals" (to be published by W. Heffer and Sons, Ltd., Cambridge) will contain a description of the Barker method and also the classification angles of some 3,000 substances.

\section{Deer in Britain}

Is his presidential address to the Bedfordshire Natural History Society and Field Club, the Duke of Bedford describes the three species of deer which are native to Britain as well as the three which have been introduced and are in process of establishing themselves in a wild state (Bedfordshire Naturalist, $4 ; 1949$ ). The native species are the red, fallow and roe deer. The former is found in a wild state in large numbers in the Highlands of Scotland, while a few exist in various parts of England. Possibly a true native, the smaller fallow deer is at present found as ancient wild herds in the New and Epping Forests. The roe deer is still widely distributed in Scotland, and, after becoming extinct in England some centuries ago, has been successfully re-introduced in some districts, notably in Dorset. The three introduced species are the Japanese sika, the Reeve's muntjac from southern China and the Chinese water deer. Smaller than the fallow deer, the Japanese sika is found in certain forests in Scotland and in Dorset. The Reeve's muntjac is the second smallest deer in existence and is no larger than a field spaniel it was first released in Woburn Park, Bedfordshire, and from there escaped to several neighbouring counties. The Chinese water deer is peculiar in that the male has no antlers; none has been deliberately released but some escaped from Woburn Park during the War. Père David's deer, which, though not native to, nor living at liberty in, Great Britain, is represented almost exclusively by the three to four hundred animals which live in Woburn Park, was also described.

\section{Problems of Infancy and Childhood}

IN order that investigators in different fields of research may make their contribution to a particular medical problem, the Josiah Macy, Jr., Foundation, of 565 Park Avenue, New York, arranges a series of two-day annual conferences. Attendance at each conference is limited to twenty-five, so that all members may participate fully in discussion. The third conference was held in 1949 and considered problems of infancy and childhood. The transactions have now been published as a report which, so that a wider group of investigators and students may share the essential quality of the conference, preserves the informal nature and tempo of the discussions. Among the problems discussed were the anxieties of mothers as revealed to physicians, the psychology of mothers and children upon their return from hospital, and observations on the emotional reactions of children to tonsillectomy and adenoidectomy.

\section{Apia Observatory, Western Samoa : Annual Reports for 1940-47}

THE annual reports of the work of the Apia Observatory, Western Samoa, for 1940-47 have recently been received (Wellington: Government Printer). Each covering about 140-160 pages, they have been issued under the authority of the Hon. K. J. Holyoake, minister of scientific and industrial research, New Zealand, and provide comprehensive details of the progress in the various sections. There is a resident staff, varying in number but usually consisting of about seven, engaged in geophysical and meteorological work, and two clerical staff; about nine others are recruited locally. There is a programme of tidal observations, and routine scalings of tidal records are sent to the United States Coast and Geodetic Survey, Washington, D.C. Towards the end of 1947 a new magnetograph calibrator was installed in the clock-room of the main office buildings and connected by underground cable with the Gauss House containing the recording system.

\section{Monetary Gift to the University of Hong Kong}

A GIFT of $£ 250,000$ has recently been made by Great Britain to the University of Hong Kong from funds set aside for higher education under the Colonial Development and Welfare Act of 1945. This gift has arisen out of plans for developing the University which were drawn up in 1946 by the Hong Kong University Advisory Committee. These plans were modified from time to time in the light of further discussions and finally resulted in a minimum development programme involving a capital expenditure of at least $£ 500,000$. A Treasury grant of $£ 250,000$ was given nearly three years ago as a gesture by the British Government towards the rehabilitation and development of the University, which was extensively damaged and looted during the Second World War. The money was untouched pending discussions 